\title{
Redes intelectuais hispano-americanas na Argentina de 1920*
}

\author{
Karina R. Vasquez \\ Tradução de Sergio Miceli e Evania Guilhon
}

M artín Fierro (1924-1927), uma das principais revistas das vanguardas argentinasnos anos de 1920, como assinala Beatriz Sarlo, "converteu o campo intelectual argentino no cenário de uma forma de ruptura tipicamente moderna" (Sarlo, 1983; cf. Romano, 1984; M assiello, 1986; Sarlo 1988; Salas, 1995). C ertamente, no momento de sua aparição, $M$ artín Fierro não era um empreendimento isolado: já desdea R eforma U niversitária, os jovens quese autodenominavam a "nova geração" sustentavam com ênfase distinta, a partir de empreendimentos compartilhados, uma vontade de ruptura com idéias e práticas da geração anterior, apelando freqüentemente para a necessidade deuma ampla renovação estética eideológica. Contra o positivismo, os excessos verbais do modernismo ${ }^{1}$ e a incipiente profissionalização da ge ração anterior, esses intelectuais - a mai oria nascida em começos do século XX - propunham-sea levar a cabo um esforço de atualização da cultura.

Alguns dos projetos que deram visibilidade a esses jovens intelectuais tiveram duração efêmera, como os três exemplares da primeira época da revista Proa, em 1922, ou a revista mural Prisma, sobre cuja fundação Borges (1987) dá um interessante testemunho:

Prisma, fundada em 1921 e com uma vida de dois números, foi a primeira das revistas que editei. N osso pequeno grupo ultraísta estava ansioso por possuir uma revista própria, porém uma verdadeira revista era algo que estava além de nossos
*Agradeço os comentá rios e as sugestões críticasformuladosno seminário "Redesintelectuais e história social da cultura: Análises e novas perspectivas deabordagens", em particular a Sergio M iceli, H eloisa Pontes, Lygia Sigaud, Ângela Alonso, Élide Rugai Bastos, Maria Arminda do N ascimento Arruda, Adrián Gorelik e Jorge $M$ yers.

1. Refiro-me aqui ao movimento literário que, no dizer deReal deAzúa (1986), agrupou importantes escritores latinoamericanos "cujo período criativo, juvenil etentativo transcorreu entre 1885 e1905". Entreseus 
traços característicos cabe destacar a "vontade de beleza como um valor isolável em si mesmo" e a busca de uma escrita enriquecida lingüística e sintaticamente pelas qualidades de eufonia, ritmo, cor etc. Um dosprincipaisrepre sentantes desse movimento foi o poeta nicaragüense Rubén Dario (1867-1916), amplamenteconhecido naEspanha e na Argentina desde finais do século XIX. N o âmbito rioplatense, destaca-se a figura de Leopoldo Lugones (1874-1938), sobre quem nos deteremos mais adiante.

\section{A fórmula da "nova} sensibilidade" unidaàda "nova geração" havia sido posta em circulação por $O$ rtegay $G$ asset no seu livro El tema de nuestro tiempo (1923). Entre os jovens argentinos, a alusão à "nova sensibilidade" remete à conformação de uma "nova biblioteca", por meio da qual se exibea recepção dos debates estéticos e ideológicos que imperavam na Europa do entre guerras. A figura de Ortega y Gasset assumiu um papel fundamental nesse processo de recepção recursos. N otei como se colocavam anúncios nos muros das ruas, e me ocorreu a idéia de que poderíamos também imprimir uma "revista mural" que nós mesmos colaríamos sobre as paredes dos edifícios em diferentes partes da cidade. Cada edição era uma única folha grande e continha um manifesto e uns seis ou oito poemas breves e lacônicos, impressos com muito branco ao redor e com uma gravura feita por minha irmã. Saíamos à noite - González Lanuza, Piñero, meu primo e eu - armados de baldes com cola e brochas fornecidos por minha mãe e, caminhando quilômetros, os colávamos nas ruas Santa Fé, Callao, Entre Rios e M éxico.

Já no "Editorial" do primeiro número dessa revista aparece claramente a oposição à estética modernista do período anterior. Posteriormente registra-se o surgimento de iniciativas que tiveram maior continuidade, entre elas a revista Valoraciones (1923-1928), que reunia, fundamentalmente, jovens ligados à U niversidade de La Plata, comprometidos na luta contra o positivismo, sob a liderança de Alejandro Korn; e também a aparição de Inicial (1923-1927), revista dirigida por quatro jovens escritores (Roberto O rtelli, Alfredo Brandán Caraffa, Roberto Smith e H omero Guglielmini), e que - como aponta Fernando Rodríguez (2003) - marca explicitamente uma distância com a velha geração e assinala a emergência, entre os jovens, de um sistema próprio de consagração, mais horizontal; por último, cabe destacar a aparição da segunda fase de Proa (1924-1926), apenas uns meses depois de M artín Fierro, dirigida conjuntamente por Jorge Luis Borges (consagrado como jovem poeta a partir da publicação de Fervor de Buenos Aires em 1923), Pablo Rojas Paz (jovem crítico literário já gozando de algum prestígio), Brandán C araffa (incentivador cultural que também participava naquele momento da direção de Inicial ) e Ricardo G üiral des (que, embora não fosse um "jovem escritor", pois havia nascido em 1886, acabou por incorporar-se ativamente ao grupo à frente de M artín Fierro, por conta de seus contatos com as vanguardas francesas).

M artín Fierro mantém significativos pontos de contato com essas publicações juvenis, não apenas porque inúmeros de seus mais ativos colaboradores contribuem com artigos e resenhas em Valoraciones, Proa ou I nicial, e, é claro, compartilham um mesmo espaço nas fotos, nas comemorações e nas homenagens organizadas pela revista, mas também pelo fato de esse elenco de revistas reafirmar com insistência sua adesão a um novo acervo de idéias, genericamente aludido sob o termo "nova sensibilidade", que aparece em múltiplas ocasiões associado à atribuição geracional². 
M as M artín Fierro tampouco se caracteriza como sendo um todo homogêneo: há, no seu interior, diferenças de interesses e confrontos mais ou menos amaciados. 0 fundador da revista, Evar M éndez (1888-1955), era um publicista da geração anterior que, porém, teve êxito em convocar um amplo espectro de colaboradores, entre os quais cabe mencionar Jorge Luis Borges (1899-1986), Eduardo G onzález Lanuza (1900-1984) e Francisco Luis Bernárdez (1900-1978), que haviam participado do ultraísmo espanhol; O liverio Girondo (1891-1967), o poeta que contava com periódicas estadias na França e havia publicado em 1922 Veinte poemas para ser lédos en el tranvia; 0 então jovem poeta Leopoldo M arechal (1900-1970); 0 arquiteto Alberto Prebisch, interessado na introdução da arquitetura em Buenos Aires, o qual foi posteriormente intendente da cidade de Buenos Aires e responsável pela construção do obelisco; os artistas plásticos Xul Solar, Emilio Pettorutti, Pedro Figari, entre outros. D ois nomes da geração anterior amplamente reconhecidos nas páginas de $M$ artín Fierro são Ricardo Güiraldes (1886-1927), autor de D on Segundo Sombra, e M acedonio Fernández (1874-1952), autor que assombra por sua audácia e questionamento das convenções realistas do romance tradicional.

Apesar de todos os pontos de contato com as outras revistas de sua época e da heterogeneidade de seus colaboradores, é importante salientar que $M$ artín Fierro estabelece al gumas particularidades próprias, cujos traços identificadores podem ser apontados: a) é uma revista especificamente voltada para a renovação das linguagens literárias e estéticas, diversamente de outras publicações que - como destaca o $M$ anifesto da segunda fase de Proa - pretendem servir de tribuna a diferentes tipos de interesses capazes de aglutinar a "nova geração"; b) como sugere Sarlo (1988), a adesão ao "novo" provoca em M artín Fierro um choque mais frontal com aquelas posições das quais se poderia derivar uma estética associada à "cor local" al gumas de suas polêmicas tornam explícito o repúdio tanto às versões do nacionalismo que, já desde o centenário (1910), propunham um retorno à tradição hispânica ou indigenista, como também à exploração temática do mundo popular imigrante que os jovens escritores esquerdistas associados ao "grupo de Boedo" defendiam³; c) outro traço peculiar de M artín Fierro é o tom festivo, jocoso e irreverente com o qual a publicação interpela a "impermeabilidade hipopotâmica do honorável público".

A pós apresentar de modo sumário as principais características da revista, pretendo desenvolver aqui um aspecto pouco explorado de Martín Fierro: as formas pelas quais se pode reconhecer nesse periódico a persistên- não apenas pelas suas intervenções diretas, masprincipalmentepela ampla difusão que teve 0 empreendimento editorial da Revista de 0 ccidente. Ver López Campillo (1972, pp. 149-278) e Vasquez (2003).

3. A designação "grupo de Boedo" remete a jovens escritoresligados às correntesdeesquerda, os quais - em linhas gerais - salientavam a função social da arteedealgum modo propiciavam uma aproximação temática com os setoresimigrantesepopulares. Entreeles estavam Roberto M ariani, Elias Castelnuovo, Lorenzo Stachina, Alvaro Yunque, CesarTiempo, Pedro Juan Vignale, Luis Emilio Soto. Como as sinala Salas (1995), ainda que M artín Fierro com freqüência responda a essa postura, a riva lidade "Boedo-Florida" deveser matizada, entre outrasrazõesporqueévisível a presença dos escritores de Boedo nas páginasenas atividades realizadas por M artín Fierro. 
cia e a transformação de certos tópicos americanistas que identificam a nova geração desde a R eforma U niversitária. Com freqüência os trabal hos sobre a revista enfatizaram, de um lado, sua vocação cosmopolita e, de outro, a preocupação em fundar um nacionalismo cultural diferente (cf. Sarlo, 1983; 1988). A esse respeito, e apesar de o nomeinvocar o poema gauchesco, cumpre esclarecer que decerto M artín Fierro projetajá em seu M anifesto uma auto-imagem cosmopolita, entendendo-se o cosmopolitismo não tanto como uma valoração positiva da visi bilidade adquirida pelo imigrante numa cidade como Buenos Aires, mas também como o direito a reconhecer-se, apropriar-se ou inscrever-se na mesma linha de prospecção de alguns autores europeus contemporâneos. Se tal identidade era fundamental no momento de legitimar a introdução de novas linguagens poéticas, não menos relevanteera a pergunta sobreo que constituía "o particular", "0 característico", "o autêntico" e como utilizá-lo para construir uma voz própria, original e potente, em condições de embocar a literatura argentina no cânone da cultura universal. O u seja, o nacionalismo cultural em M artín Fierro remete àquela versão do nacionalismo que, em consonância com a tradição liberal, formula a questão dos elementos identitários, subordinada neste caso à construção de um programa de renovação estética.

Pretendo mostrar aqui uma perspectiva capaz de aliar a afirmação cosmopolita e a busca de um novo nacionalismo cultural ao tópico americanista tão reiterado em $M$ artín Fierro - entendido como a afirmação do pertencimento a um horizonte americano que evitava, cuidadosamente, qualquer definição essencialista dessa identidade. Segundo essa hipótese, no interior da revista, a vocação cosmopolita tem um limite concreto, fixado pel os contatos logrados por seus diferentes colaboradores; e a tensão em direção a um novo nacionalismo cultural não se mantém sem conflitos. D iante desses problemas, o tópico americanista - já consolidado em 1925 pelos contatos iniciados na Reforma U niversitária de 1918 - permitia legitimamente afirmar a particularidade, sustentar uma série de redes que favoreciam a difusão da revista e, ao mesmo tempo, evitar o adiamento da discussão em torno de um "passado comum", que nem todos os participantes da revista se mostravam dispostos a resgatar.

Para desenvolver amplamente 0 tema, dividiremos este trabalho em três partes: a primeira pretende explorar de maneira geral como se concretiza a referência americanista em $M$ artín Fierro; a segunda relaciona esse posicionamento com os novos sentidos adquiridos pelo americanismo a partir de repercussões e contatos da Reforma U niversitária; e, por último, 
a terceira parte almeja explicar quais foram as dificuldades - surgidas no interior da revista, como conseqüência dos limites e desacordos suscitados tanto pelo cosmopolitismo como pelo nacionalismo - que estão na raiz da apropriação desse tópico.

$\mathrm{N}$ a capa do número 18 de M artín Fierro, sob um título impresso em maiúsculas, destacam-se duas fotografias contrapostas: numa, a imagem de um índio em pé, com a mão direita sobre o peito e a esquerda estendida, sublinhada pela breve legenda "Asteca anônimo (bem)". A seu lado a fotografia de outra escultura, dois homens lutando como gladiadores, e de novo, abaixo, a legenda: "Irurtia (mal)". Em seguida, a nota de Alberto Prebisch discorre sobre a falta de "personalidade" da obra de I rurtia: suas esculturas - segundo a crítica dura de Prebisch - não passam de mera cópia, eclética, de al gumas influências dominantes, $M$ ichelângelo, D onatello, oS neoclássicos e Rodin. "A personalidade do senhor Irurtia", disse Prebisch (1925a), "éfumaça em suas mãos". D e resto, sequer uma palavra que explique o contraste com o "asteca anônimo". Por que esse gesto necessita al guma explicação? Porque justamente naqueles anos Prebisch - então um jovem arquiteto recém-chegado da Europa - inicia uma série de significativas polêmicas em defesa da introdução do M ovimento M oderno, contra as buscas identitárias dos defensores do estilo neocolonial, como Angel Guido ou M artín N oel. Assim, por exemplo, enquanto Angel Guido defendia que o caminho para desenvolver uma arquitetura própria passava pelo aprofundamento e recuperação das formas americanas pós e pré-colombianas, Prebisch, ao contrário, considerava prioritário atender à relação entrea arte e as exigências atuais, resgatando da tradição "apenas o imanente, isto é, os valores racionais do clássico" (N ovick, 1988).

$M$ eses mais tarde, a revista recorre ao mesmo procedimento gráfico: na página 2 do número 24 , sob o título “D oisconceitos deescultura”, são apresentadas duas figuras: a mulher nua que esconde seu rosto sob uma rocha nos faz lembrar de imediato Rodin, e a reiterada legenda sanciona: "Losé Llimona: péssimo". A seu lado o "Asteca anônimo: magnífico"4. D esta vez nem mesmo aparece, em seguida, a nota explicativa de Prebisch, apenas uma menção ao passar à página seguinte, que ressal ta o quanto "nossos críticos" amiúde se perdem nos elogios de "mediocridades tão evidentes como I rurtia ou Llimona". N enhuma palavra a respeito de por que o termo de
4. "D os conceptosdees cultura", M artín Fierro, ano II, 24: 2, 17 out. 1925. Ver também Prebisch (1925b). 
5. No mesmo número em que se realiza a crítica a Irurtia, no extre mo superior direito da páginaapareceafoto de uma cerâmica peruana com uma legenda que destaca a intensidade expressiva e a simplicidade dos recursos da obra.

6. Jovem poeta chileno, dirigiu a revistaClaridad (1922) no Chile, daqual também participavaseu amigo Pablo Neruda. Suapoesiafoi divulgada fragmentariamente em jornais e revistas como Claridad, Atenea, ZigZag; publicou, em vida, apenas um livro de crônicas, Chilenos em Paris (1928), reeditado no Chileem 2003 pelaEditora U niversitaria.

7. Reconhecido poeta peruano, que transcendeo simbolismo modernista e se converte no elemento deunião com a nova poesia. É significativaa admiração que Ihe concede a revista Amauta (1926-1930), uma das publicações mais relevantesdarenovação estética e política desse país, dirigida por JoséC arlos M ariátegui.

8. Villaurrutía era um dosprincipaisnomesde "Contemporáneos" (as- comparação com essa "falta de personalidade" é, em ambos os casos, um "asteca anônimo". Talvez a pergunta seja demasiado trivial, mas o quefaz ali o "asteca anônimo"? A que universos de sentido remete essa inserção do "asteca anônimo" como termo positivo de comparação? Como se explica, na constelação queconstrói M artín Fierro, o esforço de Prebisch para exibir 0 "astecaanônimo" ou a cerâmica peruana como exemplo deartemoderna?

É importante assinalar que na própria revista essa referência não aparece isolada. Já no número $7, \mathrm{M}$ artín Fierro anuncia a partida de O liverio Girondo em "missão de confraternização artística e intelectual", uma viagem por diversas capitais americanas e européias, com a incumbência de divulgar várias revistas (a própria M artín Fierro e também Inicial, Valoraciones, La Cruz del Sur e Teseo). 0 propósito declarado é estabelecer laços, contatos, vínculos que viabilizem - como diz a revista - um "verdadeiro intercâmbio de produções, revistas, livros, idéias, poesia, arte". Ao longo de diversos números, $M$ artín Fierro noticia as andanças de Girondo e os resultados desses contatos. D e fato, o número 10/11, sob o título "Poetas do Chile", reproduz um famoso poema de Pablo N eruda (1904-1973) e outro de Alberto Rojas Giménez (1900-1934) ${ }^{6}$; no número 12/13 publica-sea colaboração deum poeta peruano, JoséM aría Eguren (1874-1942)7\% sem dúvida, porém, os contatos que redundam em maior número de colaborações, ao longo do tempo, são os estabelecidos com M adri e M éxico. M artín Fierro segue de perto a visita dos pintores R odríguez Lozano (18961971) e Julio Castellanos (1905-1947), acompanha e apóia suas exposições na Associação "Amigos da Arte", interessa-se pela "nova poesia mexicana", publica artigos de Xavier Villaurrutía (1903-1950) ${ }^{8}$ eAlfonso Reyes (1889-1959), recepciona revistas mexicanas como La Antorcha. Em suma, no geral, M artín Fierro manifesta claro interesse pela aproximação e intercâmbio com os intelectuais mexicanos, interesse que, embora se traduza em nomes e colaborações após a viagem de Girondo, já se fazia notar antes. Assim, por exemplo, em "Acotaciones a un tema vital", Serge Panine propõe-se a explicar (e, ao mesmo tempo, também defender) a novidade que trazem as obras dos novos escritores ligados a M artín Fierro, e para isso seus argumentos aludem a dois traços fundamentais:

- 0 primeiro tem a ver com a filiação desses textos às "orientações atuais" e à "sensibilidade do momento", esse "foco comum" que Panine não consegue definir com precisão, o qual, não obstante, é compartilhado em geral pelas "manifestações da arte em qualquer parte do mundo". 
- O segundo traço insiste em sublinhar que essa juventude se propõe também como "argentina, porque forma a personalidade de nossa raça, porque plasma em si o corpo espiritual denossa idiossincrasia nativa" (Panine, 1924, p. 2).

0 exemplo paradigmático dessa síntese entre o universal e o particular é o M éxico de José Vasconcelos:

Q uem acompanhe de perto o movimento universal em todo gênero de atividades não pode deixar passar inadvertidamente a efervescência dos países sul-americanos, onde palpita a olhos vistos o mesmo anseio de independência e de consolidação das características autóctones. 0 M éxico, que lidera essa marcha, conseguiu plasmar em seu movimento inicial toda uma labuta patriótica de verdadeiro mérito. D esde Vasconcel os até Rivera, literatura e pintura, uma plêiade de intelectuais se esforça para destacar - e o consegue - os valores imponderáveis que agitam 0 continente (Panine, 1924).

M éxico como exemplo, mas também como abreviatura que mostra, resume e condensa essa síntese. M éxico como paradigma, mas também como espelho no qual se reflete ao menos uma imagem - ideal, porém possível - do intelectual americano, imagem que nos incita a explorar 0 momento em que se constitui para a "nova geração" essa valoração positiva do M éxico, associada à circulação de idéias e contatos, propiciados pela Reforma Universitária.

Sabemos que a Reforma U niversitária de 1918 transformou um conflito rigorosamente local da U niversidade de Córdoba (dos estudantes com a hierarquia católica, a qual dispunha de uma grande adesão do corpo docente) em um chamado à ação e ao protagonismo da juventude americana. Já no M anifesto de 21 de junho de 1918, que se intitula "La juventud argentina de Córdoba a los hombres libres de Sudamérica", é possível ler 0 impacto de acontecimentos como a grande guerra e a revolução russa, no momento em que o discurso contrasta a "imobilidade senil" das "sociedades decadentes" ao vigor e ao heroísmo da juventude:

A rebeldia irrompida agora em Córdoba é violenta porque aqui os tiranos haviam estado cheios de soberba e era necessário apagar para sempre a recordação dos sim chamado devido a umadas revistas do grupo, surgida em 1928), considerado um doscírculos literários mais importantes do período entre as guerras. Entre as características do grupo, M aristany (1992, p. 12) assinala 0 apolitismo e a busca de um equilíbrio entretradição e modernidade, temas que 0 diferenciam do movimento estridentista deM anuel M aples Arce esugerem uma linhade afinidades com $M$ artín Fierro.

9. Muito possivelmente "Serge Panine" é 0 pseudônimo de algum dos colaboradores de M artín Fierro. 
contra-revolucionários de maio. As universidades têm sido até aqui o refúgio secular dos medíocres, o rendimento dos ignorantes, a hospitalização segura dos inválidose- o queéainda pior - o lugar ondetodas as formas detiranizar einsensibilizar encontraram a cátedra que as ditara. As universidades chegaram a ser assim o fiel reflexo destas sociedades decadentes que se empenham em oferecer o triste espetáculo de uma imobilidade senil. [...] Então a única porta que está aberta para a esperança é o destino heróico da juventude. 0 sacrifício é nosso melhor estímulo; a redenção espiritual das juventudes americanas, nossa única recompensa, pois sabemos que nossas verdades - tão dolorosas - são as de todo o continente. [... ] A juventude já não pede. Exige que se lhe reconheça o direito de exteriorizar esse pensamento próprio nos corpos universitários por meio de seus representantes. Está cansada de suportar os tiranos. Se foi capaz de realizar uma revolução nas consciências, não pode desconhecer a capacidade de intervir no governo de sua própria casa. A juventude universitária de Córdoba, por intermédio de sua federação, saúda os companheiros de toda América e lhes incita a colaborar na obra da liberdade que inicia (Portantiero, 1987, pp. 131-136).

10. "M anifiesto del Centro de Estudiantes de la Universidad deD erecho de Buenos Aires", na inauguração dos cursos deextensão universitária (cf. Cuneo, 1974, p. 23). 11. "Discurso del PresidentedelaFederación Universitaria Argentina" no I Congresso $\mathrm{Na}$ cional de Estudantes (1918), na Federación UniversitariadeBuenos Aires (cf. Fuba, 1959, p. 50).

Esse apelo da "juventude argentina de Córdoba" suscitou rapidamente o entusiasmo e a adesão de seus col egas da U niversidade de Buenos Aires e, mais particularmente, da U niversidade de La Plata, onde se multiplicaram os congressos, as greves e os discursos que, mantendo na sombra a demanda estudantil inicial pela participação no governo universitário, acentuavam sobretudo as referências a um tempo em que haviam sido liquidadas "formas sociais que durante séculos regeram o mundo"10, conclamando à "renovação dos valores intelectuais e morais"11. C omo assinalou O scar Terán (1998/1999), épossível ler ali - nos discursos que insistem em questionar a democracia parlamentar, no menosprezo dos "políticos profissionais" e na obrigação do intelectual de ir ao encontro do "povo" para constituir-se em seu guia - a vontade de se autopropor para uma função aparentemente disponível: a de liderança "espiritual" e política; um magistério que, aos olhos desses jovens, a principal força política triunfante nas eleições de 1916 - 0 radicalismo - não estava em condições de exercer, dada a brutal mediocridade de seus quadros dirigentes.

É certo que, no âmbito local, essas expectativas em grande medida se viram frustradas, pois, como observa $\mathrm{H}$ alperín D onghi (2001), nem 0 "povo" nem o "proletariado" mostraram-se muito identificados com a "causa dos estudantes"; tampouco essa posição conquistou uma clara hegemonia no interior das próprias estruturas universitárias. D e fato, por volta de 
1920-1921, o movimento reformista estava quase agonizante, com risco de perder seu impulso transformador nas pequenas lutas pelo poder no interior de cada uma das instituições universitárias. É nesse momento que uma rede de contatos internacionais - com os estudantes peruanos, com 0 M éxico de Vasconcelos e também com Romain Rolland e o grupo Clartél, presidido por H enry Barbusse - se faz presente, revitalizando e expandindo os horizontes do reformismo.

N essa direção énecessário ressaltar um acontecimento crucial: o I Congresso Internacional de Estudantes U niversitários, realizado no M éxico em 1921, e ao qual comparece uma delegação argentina, presidida pelo estudante platense H éctor Ripa Alberdi. Segundo o testemunho ligeiramente posterior de Pedro H enríquez U reña, "o M éxico interessou-o profundamente: seduziu-o sua profunda agitação amparada pela solene paz de sua natureza. E voltou à sua pátria com seus companhei ros para comunicar a todos a fé no M éxico novo" (1924, pp. 94-96). D e fato, a revista Valoraciones, que surge no cenário platense em 1923, revela a expansão dessa "fé no M éxico novo": as cartas de Vasconcelos, a divulgação dos novos pintores mexicanos, a visão positiva da ação revolucionária, a propaganda sobre os livros editados pela Secretaria de Educação Pública M exicana (propaganda que ocupa uma página inteira, embora a venda se realizasse "no D epartamento Editorial do edifício da Universidade do M éxico"), enfim, inúmeras outras referências nos sugerem a importância e a centralidade que repentinamente suscita essa "fé no M éxico novo". Por quê? Por que de chofre essa sedução, se o M éxico era um país ainda sacudido pelas conseqüências da revolução, e mal conseguia vislumbrar uma precária estabilidade política ${ }^{12}$ ?

Porque ali, por ocasião daquele congresso de estudantes, esses jovens argentinos conheceram de perto o projeto vasconceliano, que ressalta no discurso público algumas premissas (cf. Blanco, 1977, pp. 68-128):

- Já nos Estudios indostánicos (1919), Vasconcelos propunha a necessidade de acabar com o monopólio da Europa como modelo histórico a seguir. Diante dessa "civilização" esgotada, os mundos jovens (América, mas também Rússia e Índia) deviam aproveitar a força de sua barbárie para forjar uma "personalidade", uma cultura totalmente nova. Parafraseando Spengler, se para o 0 cidente a decadência é inexorável, havia chegado o momento de a América reivindicar o seu não-pertencimento a essa "civilização".
12. Com a presidência constitucional deO bre gón, em 1921, começa um período de pacificação einstitucionalização dasforças desencadeadas pela violência da década anterior; entretanto, essa paz interna não dura muito: em 1923 irrompe a dissidência de Adolfo de la H uertae, em 1926, começa a chamada "guerra cristera", que estenderia a violência armada até 1929. Ver Aguilar Camín (2000, pp. 97-169). 
- Embora houvesse em Vasconcelos a exaltação da barbárie e o mito, ele considerava, no entanto, que essas forças bárbaras, reprimidas, não desenhavam por si mesmas uma cultura. Essa cultura se enraizaria no esforço de síntese, na mestiçagem, na mescla que permitiria a essas forças cristalizarem uma personalidade.

- Por último, essas premissas confluem num programa de redenção cultural: eram os intelectuais e os artistas que, primordialmente, deviam encampar a tarefa de realizar essa síntese; tar efa particularmente urgente no M éxico, onde o "exército dos educadores" devia substituir o "exército dos destruidores". Simplificando um pouco, poder-se-ia sustentar que para Vasconcel os era essencial uma estética que, ao resgatar as forças bárbaras oprimidas, ou seja, ao resgatar o índio, realizasse a unidade cultural da nação. Essa unidade cultural era considerada um caminho que conduziria ou facilitaria, quase naturalmente, o objetivo da unidade política.

D ecerto, essas idéias não se originaram de Vasconcelos, e de fato eram

13. Eraamplamenteconhecido o episódio protagonizado por Vasconcelos, então reitor da universidade: em 12 de outubro de 1920, ele pronunciou um duro discurso contraJuan $\mathrm{Vi}$ centeGómez, ditador da Venezuela, com quem O bregón mantivera relações diplomáticas. 0 subsecretário de RelaçõesExteriores desautorizou Vasconcelos, porém este se negou a pe dir desculpas ou retratar-se, preferindo renunciar. Nesse momento acudiu publicamente para defendêlo Plutarco ElíasC alles, então minis tro da Guerra. Vasconcelos não foi afastado. tópicos que circulavam no âmbito rio-platense antes do famoso congresso estudantil de 1921. A virtude de Vasconcelos, todavia, foi unir essas premissas num único raciocínio e derivar do americanismo que destacava as potencialidades desse "mundo jovem" um projeto concreto de nacionalismo cultural. Vale dizer, a sedução exercida pelo M éxico, o fato de que essa experiência passou rapidamente a ser visualizada como um "modelo de reconstrução política e cultural" (Yankelevich, 1997, pp. 266-288), foi facilitada, porque, desta feita, quem pronuncia tal discurso já não é um estudante que a duras penas consegue convocar uma greve, mas um ministro que ascende a esse posto político sem abandonar suas prerrogativas como intelectual ${ }^{13}$, e também, ao mesmo tempo, consegue materializar esse discurso em edifícios, em edições populares dos clássicos, em revistas como El maestro etc. O utro dado que contribuiu para fixar uma impressão positiva é a disposição de Vasconcelos em oferecer um lugar relevante em sua gestão aos intelectuais: jovens e veteranos, pintores, poetas e ensaístas, muitos dos quais regressam da Europa dispostos a empregar-se a serviço do Estado, a fim de colaborar - com saberes e técnicas específicos - na construção de uma cultura nacional. Sem dúvida, a "nova geração argentina" já então percebia que não podia esperar nenhuma convocação idêntica por parte do Estado nacional. Porém, ao incluir-se nesse horizonte de relações em muitos casos hispano-americanas - ou ibero-americanas, como 
gostava de chamá-las o próprio Vasconcelos - , não faziam senão reforçar a convicção de que, mais longe ou mais perto do Estado, com ou sem seu apoio, de todas as formas cabia-lhes, como jovens intelectuais americanos, lutar por essa síntese na qual devia expressar-se uma "personalidade própria".

O utros motivos, no clima de idéias da época, contribuíram para reafirmar a convicção de que essa era a tarefa pendente da qual devia ocupar-se o intelectual americano: refiro-me ao chamado a "reconciliar a arte com a vida", Iema muito difundido na Europa já antes da Primeira Guerra. Como assinala Peter Bürger (1993, pp. 90ss.), é possível considerar que a ação das chamadas vanguardas históricas no princípio do século XX dirigia-se em geral contra a noção de autonomia, ou melhor, contra uma forma de funcionamento da arte que implicava uma perda de sua "função social" e sua correlata separação da práxis vital, da vida cotidiana. Contra tal separação, contra o isolamento da arte e seu refúgio na "perfeição formal" do esteticismo, os diversos movimentos de vanguarda europeus defenderam a possibilidade de criar uma nova práxis vital a partir da arte, ainda que não sem opiniões divergentes. Russell Berman (1988, pp. 120-121) critica a posição de Bürger e matiza essa perspectiva, afirmando que poderia sustentar-se uma continuidade dialética entre o ideal de autonomia propiciado pela moderna cultura burguesa e as vanguardas. Isto é, nem o ataque das vanguardas é um ataque completamente externo aos ideais e às promessas de felicidade dessa cultura burguesa, nem os vanguardistas estavam sós na hora de sustentar o rechaço à estética idealista do século XIX: tal como aponta Berman, esse rechaço era compartilhado em textos literários e reflexões teóricas de autores que podem ser reconhecidos muito mais como "modernistas" do que como "vanguardistas" (os exemplos de Berman são Thomas $M$ ann, Ernest Jünger eAlfred D öblin). Por fim, Berman nos propõe ver o modernismo estético associado às vanguardas históricas em seu apelo por construir uma alternativa poderosa diante do que aparecia como a decadente e dissecada cultura burguesa do século XIX. Essa posição nos parece útil porque os exemplos paradigmáticos de "vanguarda histórica" considerados por Bürger são, fundamentalmente, o dadaísmo e o surrealismo, movimentos que não contaram com uma recepção significativa na Argentina dos anos de 1920. A esse respeito, poder-se-ia argumentar que esse imperativo de reconciliar a arte com a vida é processado a partir do contato com autores tão distintos como Simmel, Paul Valéry ou 0 rtega y $G$ asset, os quais podemos reconhecer no interior do espectro modernista. 
14. Como explica G orelik (1999): "Aqui não se podia recorrer à tá bula rasa, poiso proble ma local por excelência eraqueatábularasanão tinha um passado acadêmico para aproveitar ereciclar, apenasum vazio a preencher, isso explica o salto sem mediações por cima da história atéosmitosdeorigem, para inventar um passado de uma 'comunidade nacional' que necessitava disso para formar-secomo tal. [...] Se para Brecht, 'o que vem destruirá o passado', para as vanguardas locais, o quevem o construirá".
Até certo ponto, a relevância da inflexão modernista poderia explicar que, embora 0 apelo para reconciliar a arte com a vida repercutisse amplamente em todo o território americano nos anos de 1920, os significados desse imperativo eram ligeiramente diferentes dos que predominavam entre seus pares europeus. Por um lado, não pesava o caráter destrutivo nem 0 combateà instituição Arte, porque essas instituições estavam apenas precariamente instaladas em nosso meio ${ }^{14}$. Por outro lado, esse voltar-se para a "práxis vital", o fato de incorporar os elementos da vida cotidiana e da cultura popular, foi interpretado no sentido de apel o para resgatar os traços do "particular". D iante dos intelectuais das gerações anteriores, a quem acusavam de haver-se perdido na imitação dos model os europeus, a reconciliação da arte com a vida que propugnava essa nova ger ação passava pela recuperação das características que afirmavam a própria particularidade. Particularidade nacional, por um lado, mas que se enxergava como parte de um conjunto mais amplo, do "mundo jovem" do horizonte americano. N esse sentido, uma das experiências, freqüentemente citada como modelo dessa conjunção entre "saberes atuais" e "conteúdo próprio", éa da pintura mexicana, em especial depois do êxito e das vastas repercussões do muralismo. Q uando M artín Fierro apresenta a exposição de Rodríguez Lozano e Julio Castellanos, destaca estes temas:

Fiéis aos museus que visitaram, com uma paixão contida por um firme espírito crítico, e impacientes por estabelecer um acordo entre sua artee a vidanova, buscaram neles a ambição - provavelmente inconsciente porém claramente manifesta de criar um estilo tomando como ponto de partida a sensação profunda e virgem que seu grande instinto artístico racial tende a transformar em concepção (Anônimo, 1925, p. 3).

III

Assinaladas as motivações e os impul sos que - em grandes linhas - desaguaram no americanismo, poder-seia agora indagar como e por quê esse tópico está presente em $M$ artín Fierro. M ais explicitamente, a questão é: sabe-se que em outras revistas da "nova geração", como Inicial, Sagi tario ou Valoraciones, essa característica aparece tanto nas colaborações recebidas Vasconcelos, Romain Rolland, M ariátegui, $\mathrm{H}$ aya de la Torre etc. - como nas referências reiteradas à política antii mperial ista nas quais pretende abrigar-se a causa reformista. M artín Fierro mantém laços de amizade e colabo- 
ração com essas revistas, porém se apresenta como um periódico sobremodo interessado na renovação estética. Tampouco dedica muito espaço ao americanismo em seu sentido antiimperialista, o qual exigia, por seu turno, o repúdio às posições políticas de Lugones - a quem as revistas platenses não hesitavam em classificar sem mais como "fascista": eis um passo que, não obstante, $M$ artín Fierro não se dispunha a dar, mal grado as oscilações manifestadas diante desse personagem. Lugones gozava nessa época de um prestígio indiscutível no campo intelectual: consagrado como poeta e ensaísta, havia realizado em El payador (1916) uma releitura do M artín Fierro de Hernández, considerando essa obra um poema épico nacional, depositário da alma da nacionalidade (Terán, 1993). A trajetória política de Lugones é complexa, e nos anos de 1920 inclinava-se para posições claramente antiliberais, antidemocráticas e militaristas. Como assinala D evoto (2002), o discurso pronunciado pelo poeta em Lima, na ocasião do centenário da batal ha de Ayacucho em 1924 ("La hora de la espada"), levantou uma onda de reações indignadas em toda América espanhola; em sua última parte, Lugones exaltava provocativamente os valores morais e os conceitos políticos que o fascismo havia incorporado ao contexto europeu. Com respeito à relação entre Lugones e M artín Fierro, D evoto (2002) aponta:

Evidentemente, Lugones era literariamente o ponto de partida da nova geração. $E$ ao mesmo tempo era um pai - ao qual, sem dúvida, faltava toda simpatia estética por parte da prole rebelde - de quem se buscava tomar distância. Assim revelam as constantes polêmicas em torno das formas poéticas, que opunham irreversivelmente as propostas lugonianas àquelas mais livres de procedência ultraísta. [...] 0 periódico esquivava-se do confronto com o Lugones político e não ia além de ironizar, ocasionalmente, o Lugones militarista. D esse modo inaugurava a interpretação que, como vimos, Borges vai popularizar, a de outorgar escassa importância às manifestações políticas de Lugones, que, a seu ver, careciam de interesse e relevância.

Por que, então, os jovens empenhados na renovação estética, a despeito de seu desinteresse pelo antiimperialismo, necessitavam apelar ao americanismo? C reio ser factível sustentar uma resposta positiva a essa pergunta, apesar de M artín Fierro mostrar-se um tanto distante desse tópico, tanto por seu cosmopolitismo (ao promover figuras como Paul M orand, Ramón Gómez de la Serna ou M arinetti), como por seu intento em fundar um nacionalismo cultural diferente. Em relação a isso, gostaria de sugerir que 
15.Ver "Suplemento explicativo de nuestro 'M anifiesto' ", M artín Fierro, ano I, 8-9: 3, 6 set. 1924. ambas as características - o cosmopolitismo e o nacional ismo - sustentamse em ampla medida no apelo a esse horizonte americano.

Veja-se, primeiro, como opera em relação ao cosmopolitismo. Ainda no seu início, M artín Fierro publicou em suas páginas a crítica severa de Roberto M ariani (1924, p. 2), que - entre outras coisas - refutou esse cosmopolitismo de M artín Fierro: "por que se posicionaram sob a chancela de tal símbolo [o gaúcho M artín Fierro] se todos possuem uma cultura européia, uma linguagem sutil e complicada e uma el egância francesa?". Embora no número subseqüente a resposta da redação enfatizasse esse cosmopolitismo, justificado, por um lado, pela necessidade de atender às "sugestões do momento" e, por outro, pelo domínio seguro da língua ("todos somos argentinos sem esforço, porque não temos de dissimular nenhuma pronúncia exótica" $)^{15}$, caberia indagar quais foram os limites dessa abertura cosmopolita. Paris era, para a maioria dos participantes de M artín Fierro, o centro indiscutível da renovação literária eestética; mas a relação com as novidades produzidas nesse centro foi, em certa medida, um tanto marginal. É verdade que não faltam alusões a Giraudoux e alguma nota sobre Paul M orand, contudo a maioria das referências ao universo parisiense provém deamigos, Valery Larbaud e Supervielle, interessados na revista por intermédio de R icardo Güiraldes, e mais adiante, em 1926, a partir das colaborações que recebem de Francisco C ontreras (um chileno radicado em Paris), M arcelle Auclair, outra jovem chilena, e seu noivo, Jean Prevost. O liverio Girondo, em seu giro euro-americano, passou por Paris, mas a mai oria das novidades que trouxe provinham do M éxico e da Espanha, onde a editora Calpe publicara seu livro Calcomanías. C om freqüência, em suas "notas", M artín Fierro informa que algum amigo ou colaborador se encontrava em viagem por Paris. Por que então, comparativamente, é tão escassa a atenção que concedia ao centro intelectual por excelência? Porquea revista não está interessada usual mente em resenhar as "novidades" do mundo contemporâneo, seu "cosmopolitismo" encobre de fato uma agenda de contatos, que no caso de Paris eram - salvo algumas exceções - bastante pobres, concentrando-se a maioria deles no âmbito espanhol e latino-americano. Percebese aliás a dificuldade de $M$ artín Fierro com os espanhóis, daí a insistência com que empenha em afirmar que "já não somos hispano-americanos". Por um lado, como mostrou Sarlo (1983, pp. 161-163), não é difícil ler os postulados estéticos de $\mathrm{M}$ artín Fierro (a predileção pela poesia, o culto à imagem e à metáfora, a necessidade de liquidar a estética exagerada do modernismo, o desaparecimento da rima ea atenção aos valores visuais e plásticos) 
em linha de continuidade com aqueles defendidos pelo ultraísmo ${ }^{16}$ espanhol. Essa convicção se reforçava pelo fato de quetanto Borges como $\mathrm{G}$ onzález Lanuza haviam participado ativamente das revistas ultraístas, e pelo interesse que os intelectuais espanhóis manifestavam pelos novos autores argentinos, em geral lidos eapreciados por aquel es num contexto que situava a renovação argentina como "filha di leta" da nova literatura espanhola.

D e fato, já no terceiro número, nas "N otas à margem da atualidade", M artín Fierro se queixa da proposta de Federico de 0 nís de "reivindicar para a Espanha nosso 'M artín Fierro', ou, mais propriamente, revelar aos parisienses seu espanholismo"17, que a revista se esforça em negar de maneira cabal. Isso não impediu que Guillermo de Torre insistisse recorrentemente sobre esses tópicos em sua "C arta aberta a Evar M éndez"18: com efeito, não deixa de ressaltar a continuidade entre "M artín Fierro" e o "fervor inovador" das revistas ultraístas espanholas como G récia, U Itra, Tableros, Cervantes e Cosmopolis, empenha-se em mostrar que são os jovens argentinos que, por meio de Girondo, têm interesse na aproximação com a Espanha e solicitam a colaboração de novos escritores espanhóis; e - talvez 0 mais relevante - comemora o fato de a França já não constituir uma "fonte inevitável de conhecimento" porque "se acentua nas repúblicas hispanoamericanas a corrente que as leva até a Espanha".

D eve-se assinalar que M artín Fierro não responde diretamente a G uillermo de Torre em 1925. A revista reage contra essa posição de maneira geral em seus artigos contra o hispano-americanismo, em que - por exemplo -, em tom um tanto prepotente, Pablo Rojas Paz $(1925$, p. 3) pergunta: "Q ual o exemplo quenos pode dar a Espanhanestemomento?"19. A despeito desses rompantes, a rejeição direta à formulação de Guillermo deTorre demorou dois anos: somente em 1927, por ocasião da famosa polêmica sobre o meridiano intelectual, iniciada com 0 artigo do espanhol intitulado precisamente "M adrid, meridiano intelectual de H ispanoamérica":

Jábasta tolerar passivamenteessa perda denosso prestígio, essedesvio constantedos interesses intelectuais voltados para a França! D iante dos excessos e erros do latinismo, diante do monopólio gaulês, diante da grande atração exercida por Paris sobre intelectuais de língua hispânica, tratemos de polarizar sua atenção reafirmando 0 valor da Espanha e o novo estado de espírito que aqui começa a cristalizar num hispano-americanismo extra-oficial e eficaz. D iantedaimantação desviada de Paris, assinalemos em nossa geografia espiritual M adri como o mais certeiro ponto meridiano, como a mais autêntica linha de intersecção entre Espanha e Europa ${ }^{20}$.
16. M ovimento estético que, por volta de 1918, agrupou poetas espanhóis e hispano-americanos em torno de um projeto vanguardista de renovação espiritual e técnica para a realização de seus ideais poéticos (cf. Dicionário eletrônico H ouaissda língua portuguesa, dez. 2001) (N . T.).

17. "Notas al margen dela actualidad", M artín Fierro, ano I, 3: 3, 15 abr. 1924.

18. Essa "Carta abierta" foi publicada em duas partes, nosnúmeros 18 e 19 da revista.

19.0 autor sustenta a respeito da Espanha: "Sua literatura está constituída, em grande parte, por comentaristas eglosadores. 0 que eles nos podem ensinar que não seja de segunda mão?".

20. La Gaceta Literaria, ano I, 8: 1, 15 abr. 1927. 
N ão há muitas diferenças entre essa proposta e aquela enunciada na "Carta aberta" de 1925. Porém, em 1927, os jovens argentinos manifestaram seu total repúdio a essa idéia, gerando uma áspera polêmica com os espanhóis. As inflamadas respostas ocuparam boa parte dos últimos números de M artín Fierro.

Com relação a essa reação tardia de 1927, poder-se-ia dizer queem 1925 M artín Fierro não estava em condições de romper ligações com o circuito espanhol, porque era um dos que manifestava maior interesse com relação à produção argentina contemporânea: a editora $C$ al pe publicara - como já se mencionou - o livro Calcomanías de Girondo; a Revista de 0 ccidente- nesse momento desfrutando de difusão e prestígio continental - acolheu as colaborações de Borges e de Girondo, resenhou favoravelmente G üiral des, manifestou receptividadeà obra deFigari e de Pettorutti; Ramón Gómez de la Serna era, nesses anos, um escritor de prestígio que correspondia generosamente à admiração que lhe tributavam os martinfierristas etc. D esse modo, em meados da década, quando estavam aparecendo e seconsolidando novas editoras, como as das revistas Proa ou Inicial, era um contra-senso romper abertamente com os contatos e os laços espanhóis que efetivamente facilitavam uma difusão continental de determinados autores. Era necessário buscar outros sintagmas, que permitissem afirmar a diferença sem caracterizála como ruptura. E um deles será 0 americanismo. Em outras palavras, como pôde M artín Fierro opor-se a essas vozes que ressaltavam sua filiação espanhola? Eis aqui dois elementos fundamentais: o pleito de pertencimento a um horizonte americano, a afirmação - no sentido vasconceliano - de um "mundo jovem" em queé factível um novo renascimento; e, em segundo lugar, os esforços tendentes à afirmação de um nacionalismo cultural. C reio estarem os doiscaminhos entrelaçados, porém um deles - 0 do americanismo - era relativamentemaisfácil que o outro. E por quê?

Foi dito que M artín Fierro não respondeu à "C arta aberta" de Guillermo de Torre, a menos que se considere como resposta a resenha sobre seu livro, Literaturas europeas de vanguardia, assinada por Borges e publicada imediatamente em M artín Fierro após a segunda entrega da carta de Torre (cf. Borges, 1925, p. 5).

A primeira parte da resenha constitui uma enunciação do tema do livro e um ardoroso elogio ao autor: "Livro tão honesto, tão grande, tão sem firulas de erudição e de opinião, é quase milagroso em pena tão jovem". Logo após esse preâmbulo elogioso, começam as críticas. Já a primeira é devastadora. Borges reprova o afã de construir genealogias, e de acomodar 
as novidades das vanguardas em uma sucessão linear em que cada movimento desloca e supera o anterior. Como disse Borges,

[...] também podemos retrucar-Ihe com seu próprio argumento e assinalar que essa primazia da sexta-feira sobre a quinta-feira, do hoje sobre o ontem, já é um achaque da quinta-feira, quero dizer, do século passado. Não Spengler, mas sim Spencer, éo pensador do "despuesismo" [palavra criada por Borges: después +ismo] de Torre.

Em suma, Borges está afirmando quea aparente modernidade do livro deve muito a uma concepção de história própria do século XIX. Como se isso não bastasse, a resenha continua: "Já me cansou a discórdia, e registro, acompanhado de toda paz, uma observação da qual sua leitura me convenceu: a influência irrecusável que osnorte-americanos têm exercido na literatura européia". E, depois de ressaltar os "nomes conhecidíssimos" de Walt W hitman, Emerson eEdgar Allan Poe, conclui afirmando: "hoje chegou a nossa vez, a dos americanos do sul, os da indolência e da serena incredulidade". Pelo contexto, é claro que esse "americanos do sul" refere-se a "nós, os escritores argentinos", ainda que a denominação de "americanos" seja relevante para frisar que a América tem algo a contrapor à Europa, diante do livro em geral (as literaturas européias de vanguarda), e de Guillermo de Torre e dos espanhóis em particular.

É interessante comparar a atitude de Torre, quase sempre destacando o papel fundamental da Espanha como promotora e cabeça das vanguardas latino-americanas, com a "Saudação" de Ramón Gómez de la Serna. Ali, o escritor espanhol apela ao tópico do americanismo em evidente gesto de simpatia pelos jovens argentinos:

Eu procuro isso queéa principal virtude do povo novo e original, sua desobediência a essa solenidade já de todo desprestigiada na velha Europa. [...] 0 novo tem que resplandecer na América onde não há nenhum velho fanatismo que detenha a aurora esperada $(1925$, p. 5).

Assim, Gómez de la Serna oferece uma versão do americanismo que em geral os participantes de $M$ artín Fierro conheciam por seus estreitos contatos com seus amigos de Valoraciones e Inicial, tópico acionado em diversas ocasiões com o objetivo de reivindicar o potencial renovador desse "novo mundo", ao inscreverem a si mesmos na lista das elites que procuravam a reconciliação da arte com a vida, e de se ampararem em um "nós" - nitida- 


\section{Escritor mexicano, foi} organizador daAntoloǵa dela poeśa mexicana moderna (1928), queserviu deplataformaparaaapre sentação e a difusão do grupo "Contemporáneos". M aristany (1992, p. 14) assinalaquetal antologia "cumpria um papel semelhanteao que desempenharia, para os poetas da geração de27, a antologia de Gerardo Diego de 32".
22. "N otasal margen de la actualidad", M artín Fierro, ano I, 3: 3, 15 abr. 1924. mente configurado em 1925 - que marcou a distância do ultraísmo espanhol. 0 utra maneira com que opera essa estratégia aparece com clareza no número 42 da revista, em que explode a polêmica sobre o "meridiano intelectual". As opiniões e as objeç̃ões dos argentinos aparecem nas páginas 6 e 7; todavia, M artín Fierro consagra as primeiras páginas do número ao $\mathrm{M}$ é xico, por ocasião da visita de Alfonso Reyes. $\mathrm{Na}$ página 2, uma "C arta a G uillermo deTorre", de Jorge Cuesta ${ }^{21}$, acusa o espanhol de elaborar juízos apressados sobre a atual poesia mexicana, ao ignorar quase tudo sobre 0 tema. A carta éduríssima, e por parte da revista é prestado apenas o seguinte esclarecimento: "M artín Fierro saúda Alfonso Reyes e, por motivo de sua presença em Buenos Aires, dedica estas páginas ao M éxico. Com elas apresenta aos argentinos al guns de seus grandes artistas e novos poetas entre os quais ele se destaca". N ada mais. N o entanto, o conteúdo do artigo - que não deixa de salientar que os juízos de Torre estavam apoiados exclusivamenteem sua ignorância - prepara o leitor para o que iráler nas páginas $6 \mathrm{e}$ 7, nas quais os jovens argentinos - desta vez sim - respondem de uma forma peremptoriamente negativa à proposta de Torre de considerar $\mathrm{M} \mathrm{a-}$ dri como o meridiano intelectual da América espanhola.

Agora, pode-se retomar a pergunta principal: tinham os matinfierristas algum outro recurso, além do americanismo, que fosse capaz de se ajustar ao tema da diferença perante os espanhóis? Já vimos, em termos gerais, não haver nenhuma proposta estética no âmbito teórico que ressaltasse as diferenças com o ultraísmo. A missão de reconciliar a "forma" com a "vida" está presente em M artín Fierro; o problema para esses jovens era encontrar quais elementos conformariam esse conteúdo tão particular da "vida", ou, ainda, como definir "o particular".

Há momentos em que M artín Fierro se esforça em propor um "tipo argentino" ou uma "sensibilidade argentina". Assim, por exemplo, no número 3, quando denuncia a pretensão de Federico de 0 nís de reivindicar para a Espanha "nossa M artín Fierro", o editorial recorre, muito precariamente, a esse "tipo argentino".

Porque não querem crer seus políticos, escritores, homens de ciência que somos hispano-americanos por alguma razão distinta da fala, que os imigrantes de vinte países diferentes, com seus idiomas, seus gostos, seus costumes e suas religiões, formaram um tipo argentino quetem muito pouco aver com o espanhol, eaindamenos com o "criollo" da colonização, eque se está elaborando aqui um tipo étnico, talvez 0 argentino definitivo, que graças a $\mathrm{D}$ eus será cada vez menos ibérico $[\ldots]^{22}$. 
Como vemos, essa declaração é paradoxal em vários sentidos. Por um lado, por sua instabilidade: o "tipo argentino" se "formou" e, ao mesmo tempo, "se está elaborando", o que, junto à alusão de que "será cada vez menos ibérico", induz a pensar que, definitivamente, esse "tipo argentino" ainda não existe. $E$, por outro lado, porque o fato de resgatar a contribuição imigrante - estratégia à qual $M$ artín Fierro recorre algumas vezes acentua o problema acerca do passado comum que, se supõe, deve afirmar uma identidade nacional. Logo, se o único embargo ao apelo espanhol éa diversidade do estrangeiro, fica pendente o problema de como o forasteiro se transforma em nativo.

A penas dois números depois, M artín Fierro publica as reações à pesquisa sobrea "sensibilidadenacional": as respostas mostram o fracasso da iniciati$v^{23}{ }^{23}$. Conquanto O liverio Girondo considerasse a pergunta um "simplesardil de M artín Fierro, pois M artín Fierro não pode duvidar da existência de uma mentalidade e sensibilidade argentinas", o certo é que a maioria dos entrevistados duvidou dessa tal sensibilidade. Existe, sim - afirmam as respostas -, um movimento geral de renovação, um movimento em direção "ao novo" que se manifesta mundialmente nos diversos campos da cultura, e a Argentina é parte dessa "atualidade". M as daí a existir uma "sensi bilidade" ou uma "mentalidade" argentinas, cujas características pudessem ser especificadas, há um abismo que nenhum dos entrevistados - nem mesmo o próprio Girondo - se atreveu a saltar.

Poder-se-ia argumentar quetanto 0 apelo ao tipo nacional como a busca por definir uma "sensibilidade argentina" são ensaios, apenastentativas que apareceram nos primeiros números da revista. Considerada de uma perspectiva de conjunto, não se pode dizer quea revista tenha perseguido a definição de um "tipo nacional", mas tinha a necessidade de resgatar alguma particularidade, para se contrapor aos espanhóis em primeiro lugar e, em segundo, para legitimar a renovação pretendida como modo de plasmar uma "personalidade própria".

N esse sentido, M artín Fierro não conta com um "tipo nacional", não conta com uma "sensibilidade" ou uma "mentalidade" argentinas, não conta com uma cultura autóctone afirmada pela tradição, nem tampouco, no geral, seus integrantes se mostraram dispostos a reconhecer aqueles produtos da cultura popular que - como o tango - ostentam a marca da hibridez ou da "mescla"24. A que recorrer, então? À inflexão da língua, à reivindicação de um "tom" próprio ou, como diria Girondo, "à fé em nossa fonética".
23. Eram duas as perguntas dessa pesquisa: 1) Vocêacredita na existência de uma sensibilida de, uma mentalidade, argentina? 2) Em caso afirmativo, quaissão suas características?As“C ontestaciones a la encuesta de M artín Fierro" aparecem no número 5/6: 5-7, 15 jun. 1924.

24. Uma das exceções maisnotóriaséa dosirmãos Enrique e Raúl GonzálezTuñón (19011943 e 1905-1974), fiIhos de imigrantesfiliados ao Partido ComunistaArgentino. 0 mais conhecido dos dois foi Raúl, que em 1933 dirigiu a revista deesquerdaContra epublicou vá rioslivros, entreosquais El violín del diablo (1926), M iércoles de Ceniza (1928), La calle del ahujero en la media (1930) e La rosa blindada (1936). Enrique publicou em 1926 um livro intitulado Tangos. M artín Fierro publicou uma elogiosaresenhado livro, assinada por $\mathrm{Ni}$ colas O livari (M artín Fierro, ano III, 33: 8, 3 set. 1926). 
Essa talvez tenha sido a maior aposta de M artín Fierro, verdadeiro centro de um nacionalismo cultural de novo tipo proposto pela vanguarda (cf. Sarlo, 1983; 1988, pp. 98-103). No entanto, gostaria de demonstrar que possivelmente esse caminho tampouco estava isento de dificuldades e desacordos, visíveis na recepção ambígua dos primeiros ensaios de Borges, Inquisiciones e El tamaño de mi esperanza, publicados em 1925 e 1926. 0 cruzamento entre a cultura européia e o "criollismo" que Borges propõe nesses ensaios por vezes desconcerta seus companheiros de M artín Fierro. $D$ e fato, na elogiosa resenha de Inquisiciones que a revista apresenta, Sergio Piñero manifesta algumas reservas:

Pessoalmente, Borges cometeu um deslize, para mim um defeito, quase sem importância, nessa recompilação de artigos publicados em várias revistas nossas e estrangeiras: seu "criollismo". Creio não ser necessário referir-se ao laço, ao rodeio nem aos potros para ser e manifestar alma de gaúcho. Em Borges, tudo isso está longe. $Q$ uase me atrevo a assegurar que constitui em sua vida uma lembrança herdada. Portanto, diz de memória. Noto algo de imaginativamente artificial no "criollismo" do poeta (1925, p. 3).

$\mathrm{N}$ a crítica de Piñero, a intenção é el ogiar a erudição de Borges, sua "clareza de idéias", seu conhecimento preciso do valor das palavras, as metáforas etc., porém ele condena o "criollismo", como um agregado artificial, como um elemento desatualizado que Borges adiciona "de memória".

El tamaño de mi esperanza provoca uma reticência ainda maior. Embora haja uma brevíssima nota crítica apresentando o livro demaneira elogiosa, não faltam as contestações, que, sem mencionar Borges diretamente, remetem sem dúvida a ele. Assim, em "Criollismo y metafísica", Antonio Vallejos afirma:

Temos um espírito notório, evidente em si mesmo por seu próprio fervor. Um "criollismo" não metafísico precisamente. Um "criollismo" que não evoca ruas mortas, saudoso de épocas e de nomes, e sim ambicioso pelo futuro, zeloso do presente como os relógios. Pampa, boleadoras, Rosas e subúrbio são acidentes de nosso "criollismo", que estarão em nós por fixação sentimental, por devoção; mas nunca por empenho. [...] Inquieta-me ver em companheiros de talento a fronte cega e os olhos nas costas. C omo não en xergam os dias de hojee sim o amanhã em seu ontem respectivo, não têm outro prazer senão a recordação; e o caminho Ihes vai escorrendo debaixo dos pés sem Ihes dar oportunidade de ambicioná-lo. Assim 
se explica este paradoxo: promover o nascimento da cultura e ao mesmo tempo clamar pelo coveiro; assim também essa nostalgia obsoleta, esse ardil de símbolos, e esse estrangei rismo temporal que se acomoda em bairros de lembranças, enquanto outros observam desconjuntar-se e crescer os edifícios da ginástica do progresso $(1926, \text { p. 3) })^{25}$.

M ais adiante, em "El gaucho y la nueva literatura rioplatense", Leopoldo M arechal (1900-1970), então um jovem escritor que será autor dos célebres romances Adán BuenosAires (1948) eEl banquetedeSevero Arcangel (1965), insiste em tratar novamente o tema:

Asletras rio-platenses, por meio deum discutível propósito denacionalismo literário, estão a ponto de adquirir duas enfermidades específicas: 0 gaúcho e o subúrbio. N ada haveria de censurável nisso se se tratasse do camponês atual, que monta um potro e dirige um Ford com a mesma indiferença; mas referem-se a esse gaúcho estatutário, exaltado por uma má literatura; a esse super-homem de papelão o qual, abandonando sua pobre lenda, quer hoje erigir-se em nosso arquétipo. [...] $\mathrm{N}$ ossa incipiente literatura deve arraigar-se no presente, nesta pura manhã em que vivemos. [...] Aferrar-se a um passado mesquinho como o nosso é revelação de pobreza (1926, p. 5; grifos meus) ${ }^{26}$.

Em El tamaño de mi esperanza, Borges também destaca a "pobreza essencial de nosso fazer", e rechaça tanto o "progressismo" - que é, diz o autor, "submetermo-nos a ser quase norte-americanos ou quase europeus, um constante ser quase outros" - , como o "criollismo" em sua acepção corrente, que "hoje é palavra de nostalgia" (1993a, pp. 11-14). Até aqui pareceria que Borges coincide com $M$ arechal na recusa a certo tipo de "criollismo"; porém, mais adiante, nosso autor retoma a "pobreza essencial de nosso fazer", assinalando:

Somos uns abandonados por D eus, nosso coração não confirma nenhuma fé, porém acreditamos em quatro coisas: em que o pampa é um sacrário, em que o primeiro compatriota é homem pra valer, no vigor dos malvados, na doçura generosa do subúrbio. São quatro pontos cardeais os que assinalo, não umas luzes perdidas (1993b, pp. 21-25) ${ }^{27}$.

Como sugerem as perspectivas de Antonio Vallejo e Leopoldo M are chal, pareceria que $M$ artín Fierro em conjunto não estava disposta a aceitar
25. Lembremosqueno ensaio que dá título ao livro Borges escreveu: " $N$ ão seengendrou nestas terras nem um místico, nem um metafísico, nem um sentidor, nem um entendedor da vida! N osso maior varão continuasendo dom Juan M anuel [Rosas]: grandeexemplar dafortaleza do indivíduo, grande certeza do saber viver [...]". O utro conhecido ensaio desselivro intitula-se "La pampa y el suburbio son dioses". Essas breves referências são suficientes para identificar claramente o interlocutor criticado por Antonio Vallejo.

26. É curioso notar que $M$ arechal mostra outra atitude diante do Borges poeta: defato, celebra o "criollismo" de Luna de enfrente em sua resenha publicadano número 26 deM artín Fierro, o mesmo em que inicia uma respeitosa polêmicacontra Lugones, a propósito do uso darimanapoe sia. A resenhasobreBorgescomeça assinal ando: "Créo quealeitura deste volume é o melhor argumento contra asvelhas teorias de Lugones". Parece-meplausível sustentar queo "criollismo" 
deBorges poetanão gera demasiados problemas, ao contrário, ofereceum modelo em contraste com o de Lugones poe ta. 0 desconcerto surge quando esse "criollismo" aparece na prosa.

27.0 ensaio começada seguintemaneira: "D uas presenças de D eus, duas realidades de tão segura eficácia reverencial que a mera enunciação bas ta para amplificar qualquer verso enos agitar o coração com júbilo íntimo e arisco, são o subúrbio eo pampa. Ambos já têm sua lenda e quisera escrevêlos com duas maiúsculas para melhor assinalar seu caráter de coisas arquetípicas [...]". M arechal (1926) não apenassublinhaqueo "subúrbio" era uma das enfermidades específicas que estavam a ponto de adquirir as letras rio-platenses, como, já no final do artigo, propõe: "Esqueça mos o gaúcho. No umbral dosnovos dias cresce outra lenda maior e maisdigna do nosso verso, posto queestáem nós e se alimenta de nossos anos".

28. D evoto (2002, pp. 8ss.) mostra que no sé culo XIX os"paisfundadores" (fundamental- esses "quatro pontos cardeais". D iante das reticências suscitadas por esses primeiros ensaios de Borges, encontramos os elogios dispensados a $D$ on $\mathrm{Se}$ gundo Sombra (1926), de Ricardo Güiraldes, em que seu gaúcho éa "síntese por excelência" (Anônimo, 1926, p. 6; cf. Sarlo, 1993, pp. 51-53), em grande parte porque o destino do protagonista mais jovem do romance é precisamente - como diria M arechal - "dirigir o Ford". Q uer dizer, diante desse "passado mesquinho", há uma tradição, um gesto do século XIX, próprio da geração de 80 , que $M$ artín Fierro recupera na insistência com que proclama queo "particular", a "nacionalidade" etc. estão num futuro que só se pode construir a partir do presente. Para M artín Fierro, parece, em certas ocasiões, não haver nada no passado superior ao presente ${ }^{28}$.

E isso suscita problemas, tal como sugere Sarlo (1983), "um feixe de contradições ingovernáveis, de um lado o sujeito nacional, M artín Fierro, e de outro os predicados europeus e cosmopolitas de renovação estética". Essas contradições acentuam-se - como tentei demonstrar - porque tanto os impul sos teóricos como os contatos nos quais se sustentavam tais "predicados europeus" exigiam o resgate do "particular". D iante das dificuldades para encontrar uma conjunção, um acordo compartilhado entrea exaltação da modernidade urbana e a recuperação de um passado pretérito ou imaginado ${ }^{29}, M$ artín Fierro recorre com freqüência ao americanismo. Essa inclusão em um "nós" mais amplo, a partir do qual a revista se situa como parte do "despertar intelectual da América Latina", serve-Ihe como carta de apresentação para sustentar seu cosmopolitismo; mas também, diante do nacionalismo de referência americanista, cumpre a função de apaziguar as discussões quanto ao lugar e ao peso que "o novo" deveria outorgar à rememoração do passado. 0 americanismo desenha um campo de inclusões que, além disso, devolvia aos jovens rio-platenses uma imagem grata, visto que com freqüência os intelectuais aludidos explícita ou implicitamente nas referências de $M$ artín Fierro viam Buenos Aires como o futuro de suas próprias cidades latino-americanas, como a "Paris sul-americana". Por isso, diante do cosmopolitismo, o americanismo oferecia a vantagem de destacar uma identidade comum; ante os problemas acarretados pela conformação de um novo nacionalismo cultural, acentuava a tensão em direção ao futuro. 
Referências Bibliográficas

Aguilar C am ín, H éctor \& M eyer, Lorenzo. (1993), A sombra da revolução mexicana: história mexicana contemporânea, 1910-1989. São Paulo, Edusp (trad. C elso M auro Paciornik).

Anônım O. (1925), "Rodríguez Lozano y Julio Castellanos". Martín Fierro, Buenos Aires, ano II, 18: 3, 26 jun.

An ôn Im O. (1926), "D on Segundo Sombra, relato de Ricardo Güiraldes”. M artín Fierro, ano III, 33, set.

BERM AN, R ussell. (1988), M odern culture and critical theory: arts, politicsand thelegacy of the Frankfurt School. M adison, The University of W isconsin Press.

Blanco, José Joaquín. (1977), Se llamaba Vasconcel os: una evocación crítica. M éxico, FCE.

Bo RGES, Jorge L uis. (1925), "G uillermo deTorre - Literaturas europeas devanguardia". M artín Fierro, Buenos Aires, ano II, 20: 5, 5 ago.

. (1926), "D ías como flechas". M artín Fierro, ano III, 36: 8, 12 dez. . (1987), "Autobiografía”. In: Rodríguez M onegal, Emir. Una biografía lite rária. M éxico, FCE.

. (1993a), “El tamaño de mi esperanza”. In: . El tamaño demi esperanza.

1a edição 1926. Buenos Aires, Espasa Calpe, pp. 11-14. . (1993b), "La pampa y el suburbio son dioses". In: . El tamaño de mi esperanza. 1ạ edição 1926. Buenos Aires, Espasa Calpe, pp. 21-25.

Bürger, Peter. (1993), Teoria da vanguarda. Lisboa, Vega U niversidade (trad. Ernesto Sampaio).

Cuneo, D ardo (org.). (1974), La reforma universitaria (1918-1930). Caracas, Biblioteca Ayacucho.

D evoto, Fernando. (2002), Nacionalismo, fascismo y tradicionalismo en la Argentina moderna: una historia. Buenos Aires, Siglo XXI.

Fuba (Federación Universitaria de Buenos Aires). (1959), La reforma universitaria (1918-1958). Buenos Aires.

Gómez de la Serna, Ramón. (1925), “Salutación”. M artín Fierro, Buenos Aires, ano II, 19: 5, 1 이․

Gorelik, Adrián. (1999), “O moderno em debate: cidade, modernidade, modernização". In: M elo M IRAN da, Wander (ed.). Narrativas da modernidade. Belo H orizonte, Autêntica Editora.

H alperín Donghi, Tulio. (2001), Vida y muerte de la República verdadera (19101930). Buenos Aires, Ariel, Biblioteca del Pensamiento Argentino, pp. 103-123. Henríquez U reña, Pedro. (1924), "Poeta y luchador". Valoraciones, 2, jan.
menteSarmientoeAlberdi) caracterizaram-se"pela férrea vontade de anular o passado, e, ao fazêlo, fundar uma nova nação que repousa sobre novas bases, sobrenovosmitos, em novos sujeitos". Ao seu modo, a versão historiográfica do general $M$ itre acentua também essatensão em direção ao futuro, enquanto plasma o mito do "destino de grandeza" quecabeà Re pública Argentina nas mãos deuma elitecaracterizada como liberal, "criolla" eportenha. Isto é, o processo deconstrução do Estado duranteo século XIX insiste particularmentenanecessidade de ruptura eabolição do passado.

29. Sarlo (1988, pp. 102-103) sustenta que essesdoistemas/modernidade urbana/recupe ração de uma Buenos Aires pretérita ou imaginada) resultam complementares no Índice da nova poesia americana, organizado por Hidalgo. Seguindo as sugestões do texto, parece-me interessante observar que esses temas também resultam centrais em M artín Fierro, porém nem sempresão complementares. 
. (1925), "Caminos de nuestra historia literaria”. Valoraciones, 7: 27-32, set.

Ló Pez Cam PILlo, Evelyne. (1972), La “Revista de 0 ccidente" y la formación deminorías

(1923-1936). M adrid, Taurus.

M ARECh AL, Leopoldo. (1926), "El gaucho y la nueva literatura rioplatense". M artín

Fierro, ano III, 34: 5, out.

M ARIAN I, Roberto. (1924), “M artín Fierro y yo”. M artín Fierro, ano I, 7, jul.

M ARIStAnY, Luis (org.). (1992), "C ontemporáneos" - JoséG orostiza, Xavier Villaurrutía,

Jorge Cuesta, Gilberto $O$ wen, Salvador N ovo - Poesías. Málaga, Anaya \& M ario Muchnick.

M ASIELLO, Francine. (1986), Lenguajee ideología: las escuelasargentinas de vanguardia.

Buenos Aires, $\mathrm{H}$ achette.

N ovick, Alicia. (1998), "Alberto Prebisch y la vanguardia clásica". Cuadernos de

H istoria, Boletín del Instituto de Arte Americano el nvestigaciones Estéticas "M ario J. Buschiazzo", Facultad de Arquitectura, D iseño y U rbanismo, U BA, 9: 117195, jun.

O RTEga y G ASSET, José. (1983), El tema de nuestro tiempo. O bras completas. 1a edição 1923. M adrid, Alianza Editorial, vol. 3.

Panine, Serge. (1924), "Acotaciones a un tema vital". M artín Fierro, ano I, 10-11: 2, out.

Perloff, M arjorie. (1993), 0 momento futurista: avant-garde, avant-guerree ea linguagem da ruptura. São Paulo, Edusp.

PIÑ ERo, Sergio. (1925), "Inquisiciones, por Jorge Luis Borges". M artín Fierro, ano II, 18: 3 , jun.

Portantiero, Juan Carlos. (1987), Estudiantes y política en América Latina (19181938): el proceso de la Reforma U niversitaria. Buenos Aires, Siglo XXI.

Prebisch, Alberto. (1925a), "Irurtia". M artín Fierro, ano II, 18: 1, jun. . (1925b), “EI XV Salón N acional. Los nuevos artistas”. M artín Fierro, ano II, 24: 5-6, out.

Real de AzúA, Carlos. (1986), “M odernismo eideologías”. Punto deVista, ano X, 28, nov. (separata).

Revista M artín Fierro 1924-1927. Edición facsimilar. (1995), Buenos Aires, Fondo $\mathrm{N}$ acional de las Artes (estudo preliminar de H oracio Salas).

Rodríguez, Fernando D iego. (2003), “Estudio preliminar". Inicial. Revista dela nueva generación (1923-1927). Edição facsimilar. Buenos Aires, U niversidade N acional de Quilmes, pp. 7-43.

Rodríguez M onegal, Emir. (1987), U na biografía literaria. M éxico, FCE.

Rojas Paz, Pablo. (1925). "H ispanoamericanismo". M artín Fierro, ano II, 17: 3, maio. 
Rom An 0, Eduardo. (1984), "Las revistas argentinas de vanguardia en la década de 1920". Cuadernos H ispanoamericanos, 411: 177-200, set.

SALAS, H oracio. (1995), "Estudio preliminar". Revista M artín Fierro 1924-1927. Edición facsimilar. Buenos Aires, Fondo $\mathrm{N}$ acional de las Artes.

SARLO, Beatriz. (1983), "Vanguardia y criollismo: La aventura de M artín Fierro". In: Altamirano, C. \& Sarlo, B. Ensayos argentinos: de Sarmiento a la Vanguardia, Buenos Aires, Centro Editor de América Latina, Colección Capítulo, pp. 127171.

. (1988), U na modernidad periférica: Buenos Aires 1920 y 1930. Buenos Aires, Ediciones Nueva Visión.

. (1993), Borges, un escritor en las orillas. Buenos Aires, Espasa C alpe/Ariel.

Terán, O scar. (1993), "El payador de Lugones o 'la mente que mueve las moles' ". Punto deVista, ano XVI, 47: 43-46, dez.

. (1998/1999), "La Reforma U niversitaria en el clima de ideas de la 'nueva sensibilidad" ". Espacios, 24: 3-7, dez./mar.

Vallejos, Antonio. (1926), "C riollismo y metafísica”. M artín Fierro, ano III, 27-28, maio.

Valoraciones (1923-1927). La Plata, vols. I, II, III e IV.

VASQUez, Karina. (2003), “D e la modernidad y sus mapas. Revista de 0 ccidente y la 'nueva generación' en la Argentina de los anos veinte". Estudios I nterdisciplinarios de América Latina y el Caribe, 14 (1).

YankeleVich, Pablo. (1997), M iradas australes propaganda, cabildeo y proyección de la revolución mexicana en el Río de la Plata, 1910-1930. M éxico, Instituto N acional de Estudios H istóricos de la Revolución M éxicana/Secretaria de Relaciones Exteriores. 


\section{Resumo}

Redes intelectuais hispano-americanas na Argentina de 1920

Este artigo se propõe a investigar as conexões entre R eforma U niversitária e vanguarda estética na Argentina dos anos de 1920, enfocando principalmente a rede de ligações, interesses e contatos que a vanguarda recebe (recolhe) da experiência reformista. Para tanto, privilegiou-se a análise da revista M artín Fierro (1924-1927) com o propósito de mostrar que, entre a vocação cosmopolita da revista e a busca de um novo nacionalismo cultural, pode-se reconhecer nessa publicação uma particular afirmação do tópico americanista. Tomado em um sentido que rejeita uma definição essencialista do "ser americano", o americanismo - como horizonte de referências e contatos - será apresentado como um dos tópicos que contribuem positivamente para resolver alguns dos dilemas da vanguarda estética dos anos de 1920.

Palavras-chave: Vanguardas argentinas; Anos de 1920; Reforma Universitária; Cosmopolitismo; N acionalismo; Americanismo.

\section{Abstract}

Hispano-american intellectual networks during 1920's in Argentina

I have intended, in this article, to investigate the connections between the higher education reformation and the aesthetic avant-garde movement of the twenties in Argentina. I focused on the influence the reformist experience, specially its net of connections, interests and contacts, had over the avant-garde movement. In order to do that I chose to analyze the M artín Fierro (1924-1927) magazine showing that in between the magazine's cosmopolitan vocation and the search for a new cultural nationalism we can recognizea particular statement of the topic of Americanism. Rejecting the essentialist definition of what "being American" means, the Americanism, as a

Texto recebido em 29/ 9/2004 eaprovado em $19 / 1 / 2005$.

KarinaR. Vasquezéprofessoraepesquisadorada UniversidadedeBuenos Aires, membro do Programa de H istória Intelectual da Universidade Nacional de Quilmes e doutoranda no ProgramadeH istóriaSocial da CulturanaPUC/Rio de Janeiro.E-mail:kvasquez@ @gmail.com. referential point, will be presented as one of the themes that have positively contributed to the solving of some of the dilemmas aroused by the aesthetic avant-garde movement of the twenties.

Keywords: Aesthetic avant-garde movement of the twenties in Argentina; University student Reform; Cosmopolitanism; N acionalism; Americanism. 